\title{
A TEORIA DA EVOLUÇÃO HUMANA EM OUTRAS ESPÉCIES: O CASO DO "DINOSAUROID"
}

\section{ARTIGO ORIGINAL}

FARAH, Leonardo de Castro ${ }^{1}$

FARAH, Leonardo de Castro. A teoria da evolução humana em outras espécies: o caso do "Dinosauroid". Revista Científica Multidisciplinar Núcleo do Conhecimento. Ano 06, Ed. 05, Vol. 12, pp. 05-25. Maio de 2021. ISSN: 2448-0959, Link de acesso: https://www.nucleodoconhecimento.com.br/historia/caso-do-dinosauroid, DOI: 10.32749/nucleodoconhecimento.com.br/historia/caso-do-dinosauroid

\section{RESUMO}

Carl Sagan (1934-1996) em seu livro: Os Dragões do Éden de 1977 sugeriu um experimento mental interessante, propondo que caso não houvesse a extinção K-T alguns dinossauros poderiam ter evoluído para uma forma humanoide. Em 1982, Dr. Dale A. Russell e Ron Séguin, escreveram um artigo sugerindo essa possibilidade. Segundo Russell, os Troodontidæ poderiam ter dado origem ao humanoide, dinosauroid que teria braços e pernas longas, tinha $1.100 \mathrm{~cm}^{3}$ de volume cerebral sendo bem habilidoso chegando ao ponto de criar ferramentas. Por isso, a mídia o chamou de Samartasaurus. Será que esse experimento mental estaria correto? Com o objetivo de explicar isso iremos contar com os artigos de especialistas, em locomoção humana: Owen Lovejoy, o especialista em cozimento, Dr. Richard Wrangham e o especialista em evolução humana, Dr. Walter Neves da USP.

1 Possuí Três Pós-Graduações Latu-Sensu. Graduado Em História Pela Uni-Bh. Especialista Em Educação Em Sociologia Pela Faculdade Noroeste De Minas Gerais. Especialista Em História Pela Faculdade Luso-Brasileira. Especialista Em História E Geografia Pelo Centro Universitário Barão De Mauá.

RC: 86090

Disponível em: https://www.nucleodoconhecimento.com.br/historia/caso-do-dinosauroid 
Palavras chaves: experimento mental, dinosauroid, inteligência.

\section{INTRODUÇÃO}

No nosso texto anterior ( $A$ Evolução Humana numa Perspectiva Observada em Star Wars), afirmamos que a bipedia humana assumiu vários formatos e configurações diferentes, devido às diferenças anatômicas entre os hominínios mais antigos, por essa razão, cada espécie tinha sua própria forma de locomoção que é "incomum" na natureza (STANFORD, 2004). Vamos propor neste texto, que o bipedalismo humano não conseguiria ser repetido, em outras criaturas, mesmo em caso, hipotético. O motivo disto seria que as mesmas variáveis adaptativas, comportamentais e alimentares que fez emergir os primeiros hominínios, teriam de acontecer novamente (WARD, 1997). O Dinosauroid teria: características humanas somadas às características de determinados dinossauros carnívoros, algo muito estranho, que desafia nossa compreensão.

\section{O QUE “ARDI” NOS DIZ?}

O Ardipithecus ramidus surgiu na literatura antropológica, em 1995, num curto artigo científico escrito pela equipe de Tim White (WHITE; SUWA; ASFAW, 1995). O que se sabia desta espécie era que habitava a Etiópia a uns 4,4 milhões de anos e possuía dentes pequenos. Ainda não sabia nada sobre sua anatomia (pós-craniano) membros superiores e inferiores. Nessa época foi descoberto um esqueleto de uma fêmea $45 \%$ completo, mas não foi publicado, isso, porque Tim White junto com uma equipe internacional de paleoantropólogos estudaram seus fósseis minuciosamente, sendo publicando seus resultados na revista: Science, em 2009. Essa pesquisa durou 14 anos. A equipe apelidou o fóssil de: Ardi (LOVEJOY et al, 2009). No ano seguinte, a Discovery Chanel fez um documentário sobre a descoberta, o programa foi chamado: Descobrindo Ardi (2010), estando disponível em DVD.

De acordo com Lovejoy, o crânio de Ardi tinha dentes pequenos, inclusive seus caninos (LOVEJOY et al, 2009). Os chimpanzés e bonobos possuem um canino RC: 86090

Disponível em: https://www.nucleodoconhecimento.com.br/historia/caso-do-dinosauroid 
extremamente grande, sendo usado para intimidar outros machos e predadores. Isto quer dizer que em algum ponto na evolução humana, os machos deixaram de competir e intimidar rivais usando seus caninos como armas.

FIGURA 1.1 - Vista lateral e do palato de um Bonobo. Bem abaixo, a vista lateral do crânio do Ardipithecus - mostrando a ausência do complexo (CP3).

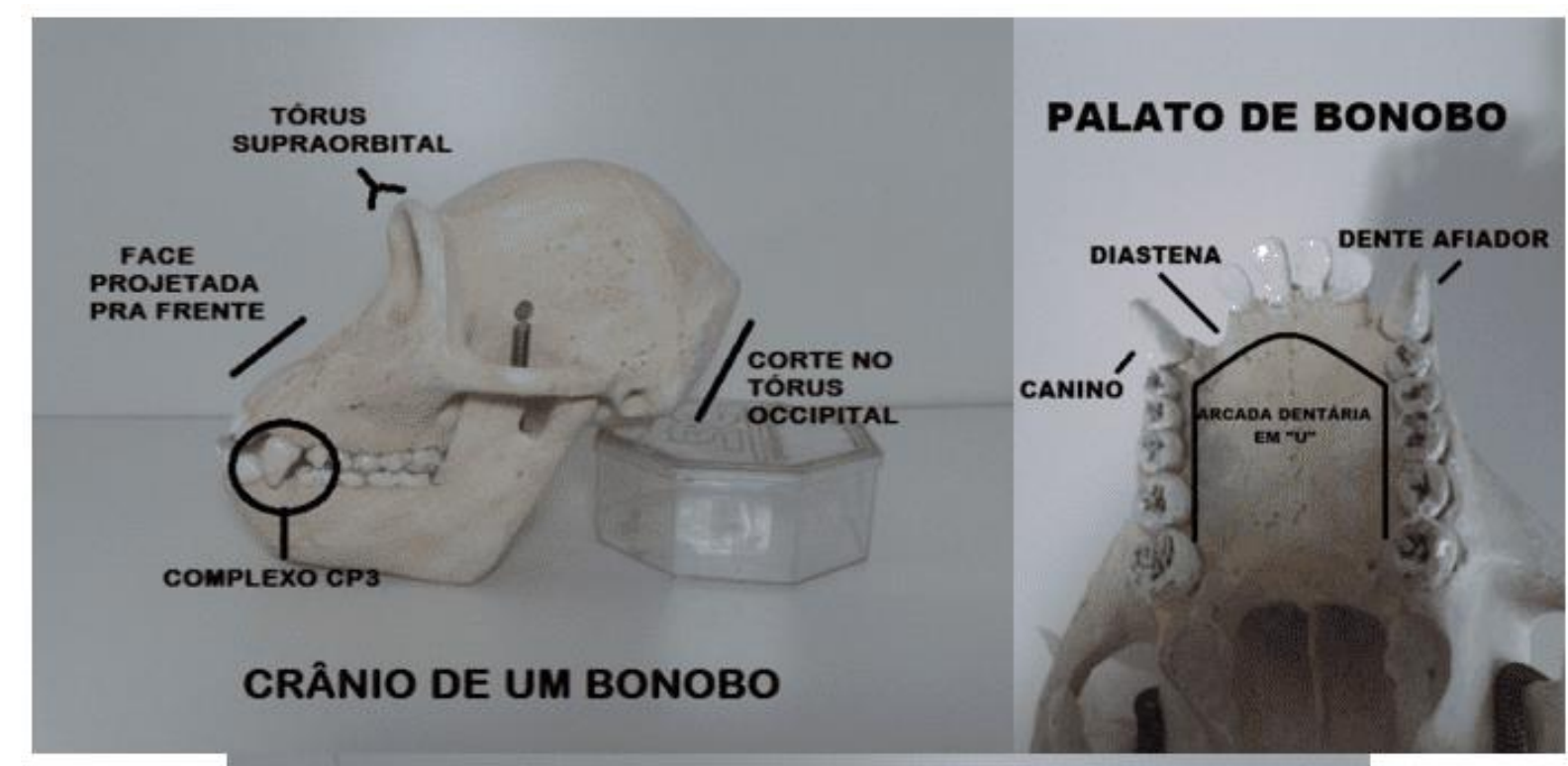

\section{CRÂNIO DO ARDIPITHECUS RAMIDUS}

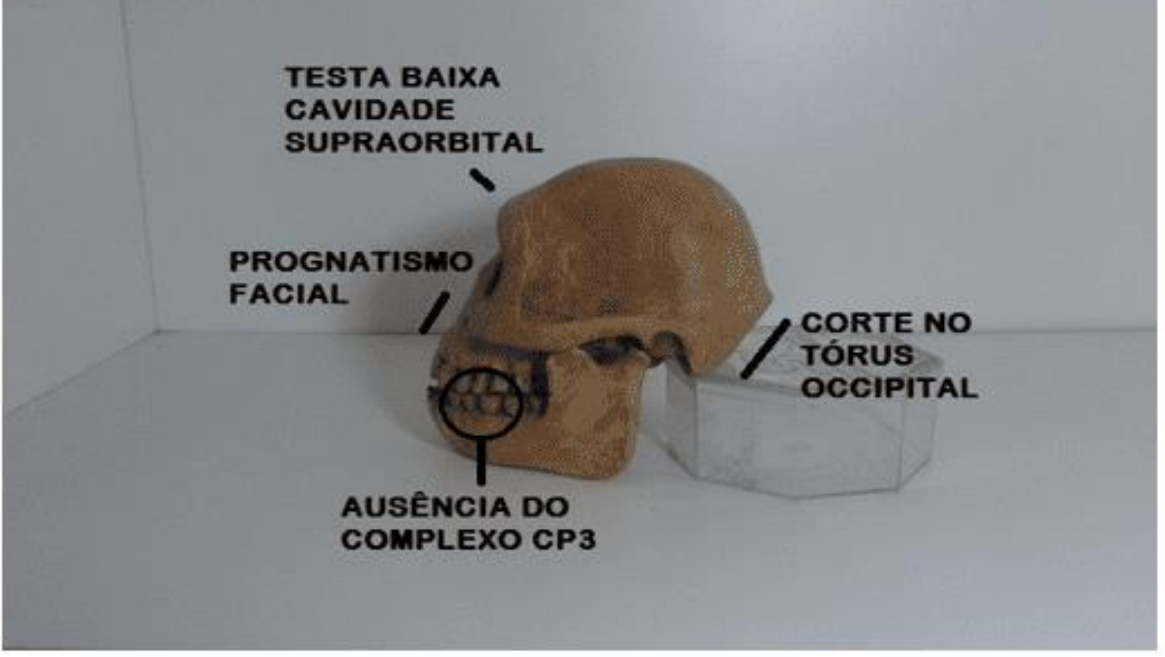

Acervo de Leonardo de Castro Farah.

That shift probably reduced male-to-male conflict and combined three previously unseen behaviors associated with their ability to exploit both trees and the land surface:

RC: 86090

Disponível em: https://www.nucleodoconhecimento.com.br/historia/caso-do-dinosauroid 
(1) regular food-carrying, (2) pair-bonding, and (3) reproductive crypsis (in which females did not advertise ovulation, unlike the case in chimpanzees)[2]. (LOVEJOY, 2009, p 74).

No que diz respeito aos dentes de Ardi, diferenciando dos dentes de chimpanzés, Dr. Lovejoy chamou isso de SCC (Sectorial Canine Complex ou Complexo Canino Setorial) (LOVEJOY, 2009). Observando o pós-craniano deste hominínio percebeuse, que sua locomoção não se deu nas savanas e sim nas árvores: "finally, the environmental context of Ardipithecus suggests that its primary habitat was not savanna or grassland, but instead woodlands"[3] (LOVEJOY, 2009, p 74e1). Neste caso, Dr. Lovejoy percebeu que Ardi possuía características arbóreas, similar aos chimpanzés.

Muitos documentários do Discovery Chanel ou Natgeo quando aborda o assunto bipedia na evolução humana de forma errônea defendendo a "Hipótese da Savana". Essa hipótese foi levantada pelo Dr. Raymond Dart nos anos 30 e 40 que afirmava que a locomoção ereta havia surgido nas savanas africanas, que os hominídeos abandonaram as árvores e foram viver em campo aberto (STANFORD, 2004). Nos anos 90 , com o aumento do número de mestres e doutores, em paleoantropologia que estudavam o plaeoclima africano provou-se que entre: 5,0-3,0 milhões de anos havia florestas cobrindo boa parte da África (STANFORD, 2004), período que Ardi viveu.

Ar. ramidus was fully capable of bipedality and had evolved a substantially modified pelvis and foot with which to walk upright. At the same time, it preserved the ability to maneuver in trees, because it maintained a grasping big toe and a powerful hip and thigh musculature. Because upright walking provided no energy advantage for Ar. ramidus (it lacked many of the adaptations evolved in later hominids such as Australopithecus), reproductive success must have been central to its evolution in early hominids[4]. (LOVEJOY, 2009, p 74).

Voltando ao tema dos caninos reduzidos, isso poderia ser uma estratégia de sobrevivência que passou por uma mudança no comportamento: sexual, social e alimentar. Isto quer dizer, que as fêmeas escolhiam machos que pudessem carregar

RC: 86090

Disponível em: https://www.nucleodoconhecimento.com.br/historia/caso-do-dinosauroid 
mais alimento. Com isso, os braços ficariam liberados para este propósito, levando a bipedalidade (LOVEJOY, 2009). De acordo com a resenha do livro do Dr. Klein elaborada pelo Dr. Walter Neves para a Revista de Antropologia da USP sugeriu que a bipedia de Ardi não tem muita relação com os chimpanzés, no sentido que se locomoção chamada de nodopedalia (NEVES; PILÓ, 2008).

Tim White matou dois coelhos com uma caixa d'água só. O Ardi não apresenta nenhum traço em seu esqueleto que indique que sua bipedia tenha se originado de um mono nodopedálico (para White, a bipedia do Ardi teria surgido de um palmígrado, com grande gracilidade e flexibilidade no punho). Portanto, o chimpanzé é um péssimo modelo para representar o tão propagado elo perdido (aqui me junto a um dos cartunistas da Folha, que em novembro de 2009 afirmou: o elo era tão perdido, mas tão perdido, que escovava os dentes na pia da cozinha) (NEVES, 2011, p 490).

O que isso significa? Ardi não tinha uma locomoção nodopedal, mas também não era totalmente quadrúpede. Como o Dr. Lovejoy já havia sugerido anteriormente, Ardi caminhava sob duas pernas, mas ao mesmo tempo, ainda era primitivo ao ser comprar aos modelos mais recentes, como os australopitecíneos. Porém, o Dr. Neves vai mais além sugerindo que "poderia" ter havido no passado remoto uma evolução de um quadrúpede que teria dado origem ao Ardipithecus.

(...) Teríamos que admitir que os primeiros bípedes teriam surgido de um nodopedálico, que desses bípedes alguma linhagem tivesse adotado, a posteriori, a quadrupedalia palmígrada, que por sua vez teria dado origem a uma outra linhagem bípede, a do Ardi. Toda essa discussão tem levado alguns especialistas a cogitar o impensável: que talvez tenha havido linhagens símias tão bípedes quanto a nossa, a dos hominínios, mas que esses monos bípedes se extinguiram (NEVES, 2011, p 491).

Se os primeiros bípedes tivessem evoluído e se extinguiram ao longo o tempo, isso mostra o quão enorme é nossa árvore genealógica humana. No que diz respeito ao pós-craniano, o fêmur e a pélvis de Ardi são parecidas com a de Lucy (Aus. afarensis) (LOVEJOY, 2009). Para White, o Aus. afarensis tinha alguma relação de ancestralidade com Ardi. O seu pé possuí um dedo opositor, prênsil, similar aos monos. Com isso, ele não poderia realizar longas caminhadas ou longas corridas. Ele

RC: 86090

Disponível em: https://www.nucleodoconhecimento.com.br/historia/caso-do-dinosauroid 
não conseguiria disparar como um velocista olímpico (LOVEJOY, 2009). Provavelmente, por esta razão, teria migrado de um local para outro poucas vezes.

FIGURA 1.2 - os pés de Ardi à esquerda, do Aus. Afarensis ao centro e do humano moderno à direita.
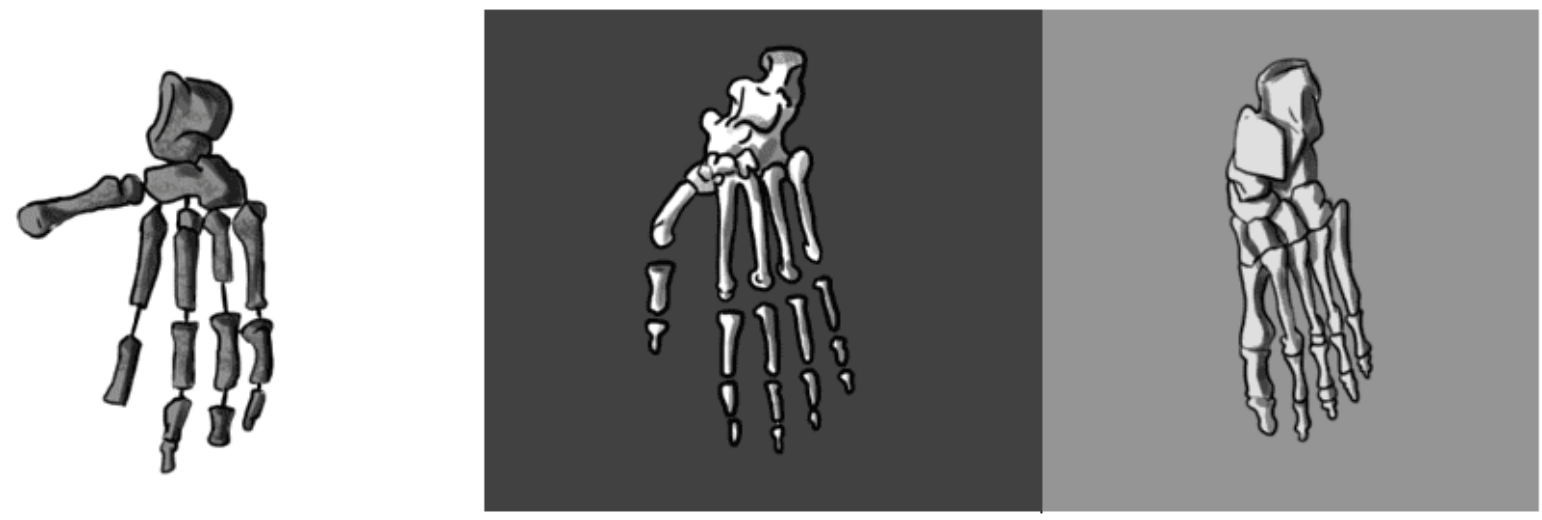

Ilustração de Danilo Borges.

RC: 86090

Disponível em: https://www.nucleodoconhecimento.com.br/historia/caso-do-dinosauroid 
Figura 1.3 - O esqueleto de Ardi (ARA-VP-6/500) publicado em 2009. O Aus. afarensis chamado de Lucy, descoberta em 1974 por Dr. Don Johnason, seu fêmur e pélvis são iguais ao de Ardi.
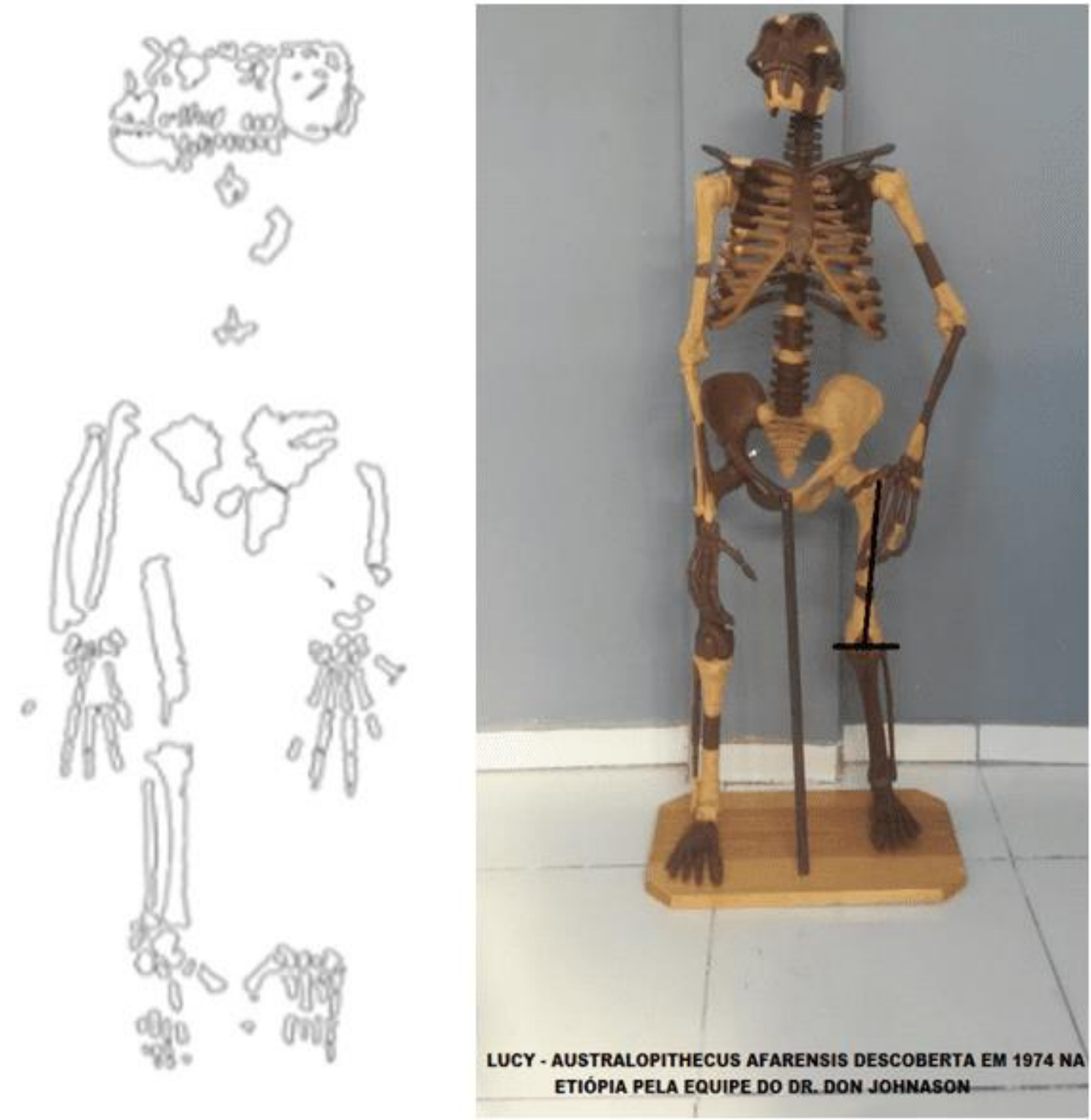

Ilustração de Felipe Lima Simões. Acervo de Leonardo de Castro Farah.

Em resumo, Ardi nos diz que sua locomoção ainda era primitiva, mas o que provocado esta postura, segundo, Dr. Lovejoy teria sido: transporte e armazenamento regular de comida, ligação de par ou parceiros e reprodução. O indivíduo que conseguisse RC: 86090

Disponível em: https://www.nucleodoconhecimento.com.br/historia/caso-do-dinosauroid 
transportar mais alimentos tinha mais chances de arrumar uma parceira e obviamente, reproduzir (LOVEJOY, 2009). Essa estratégia de sobrevivência proporcionou os meios propícios para a: Home Base tese defendida por Glynn Isaac (1937-1985), que afirmava que o alimento coletado (vegetal ou carne) era distribuído e repartido pelo grupo, em um acampamento (Home Base), e que o ato de repartir, nos fez humanos (LEAKEY; LEWIN, 1996).

\section{O DINOSSAUROID EM COMPARAÇÃO COM OS HOMINÍNIOS}

No tocante a locomoção humana, sabemos que várias espécies tinham um bipedalismo diferente de nós. Tanto, Ardi, como Lucy tinham um pé no chão e outro na árvore. É importante comentar que não existe no registro fóssil, uma evolução linear do bipedalismo humano, pelo contrário, há diversas espécies primitivas com maior eficiência do que predecessores mais recentes. Um bom exemplo seria o caso do Homo ergaster-erectus que surgiu a 2,0 milhões de anos e possuía seis vertebrais lombares, enquanto, nós temos cinco e os chimpanzés quatro. Tendo uma locomoção mais eficiente. Já os chimpanzés também são bípedes, mas são facultativos, na maioria das vezes eles andam sob nós dos dedos, chamada de nodopedalia, e passam parte do tempo nas árvores (NEVES et al, 2015).

Andar sob duas patas economiza mais energia. Segundo Leonard e Robertson (1997) fizeram um experimento interessante, eles analisaram o deslocamento de animais adultos quadrúpedes por uma determinada distância, fazendo o mesmo percurso, com um ser humano e um chimpanzé, todos adultos. O resultado foi que a cobaia humana ao deslocar sob suas pernas perdeu menos energia, que os quadrúpedes e o chimpanzé.

Outro animal que anda sob duas pernas seria as aves, herdada de seus ancestrais os dinossauros terópodas (grupo de dinossauros bípedes, com três dedos nos pés). Muitos paleontólogos, como Dr. "Jack" Horner afirma que os dinossauros não foram extintos, pois ainda existem em forma das aves. Com base nesta informação, alguns cientistas propuseram, que hipoteticamente o que aconteceria com a evolução dos RC: 86090

Disponível em: https://www.nucleodoconhecimento.com.br/historia/caso-do-dinosauroid 
dinossauros, caso não fossem extintos a 65 milhões de anos por um asteroide, que caiu no México (ALVAREZ, 1980)?

O primeiro cientista que pensou nessa possibilidade foi o Dr. Carl Sagan (1934-1996), em seu livro: Os Dragões do Éden (1977), sugerindo que o Saurornithoides[5] da família dos Troodontidae poderia ter evoluído ao um ser inteligente, caso não houvesse a extinção K-T. Sua sugestão partiu da análise de um dinossauro mais inteligente do Cretáceo Superior, que na época, ele tinha uma inteligência aguçada ao ser comparado com seus contemporâneos.

Os dinossauros mais inteligentes de acordo com o critério da relação entre massa cerebral e corporal são os Saurornithoides, cujos cérebros pesavam em geral 50 gramas pra uma massa corporal de mais ou menos 50 quilogramas. De fato, eles se assemelham ao avestruz (SAGAN, 1985, p 56).

Se não tivesse ocorrido a extinção dos dinossauros, seriam hoje as formas de vida dominadoras na Terra os descendentes dos Saurornithoides, escrevendo e lendo livros, especulando sobre o que teria acontecido se os mamíferos tivessem prevalecido? Pensariam as formas dominantes que a aritmética de base 8 era bastante natural e que a base 10 um "fricote" ensinado apenas na "Matemática Moderna"? (SAGAN, 1977, p 57).

\subsection{GRAMÍNEAS, AGRICULTURA E A SOCIEDADE COMPLEXA}

Para o Saurornithoides possa: escrever e ler e fazer cálculos seria necessário que houvesse uma sociedade complexa (escrita e matemática). Para isso seria necessária à agricultura das gramíneas e/ou tubérculos (batata e mandioca), em larga escala como (LEROI-GOURHAN, 1987). Atualmente, grande parte da dieta humana é baseada nessas plantas. Nós cultivamos: trigo (que se faz o pão, bolo e biscoito), cevada (que se faz a cerveja), aveia (que colocamos no pão e açaí), cana de açúcar (que se faz o açúcar, rapadura, melaço e a cachaça), arroz (que pode ser cozido e fazer saquê), capim-limão (que serve para fazer chá), citronela (repelente natural contra insetos), milho e centeio. Sem as gramíneas não haveria Revolução Francesa (1789-1799), que segundo Albert Soboul sugere que:

RC: 86090

Disponível em: https://www.nucleodoconhecimento.com.br/historia/caso-do-dinosauroid 
A colheita de 1788 foi desastrosa: a partir de agosto a alta se afirmou e prosseguiu sem parar até julho de 1789. A catástrofe agrícola o mercado rural, o desemprego multiplicou-se entre a mão-de-obra, a taxa do salário baixou. A queda da produção industrial (e, portanto, o desemprego urbano) pode ser avaliada em $50 \%$, a da taxa do salário de 15 a $20 \%$ enquanto o custo de vida subia na proporção de 100 a $200 \%$ (SOBOUL, 1976, p 29).

Para Kriwaczek (2018) há uma relação, entre: a agricultura e a escrita, que surgiu na Mesopotâmia como uma forma de anotar e contabilizar grãos que eram colhidos e eram entregues ao Templo e ali ficando armazenado. O que facilitou essa relação foi aumento populacional na região da Mesopotâmia provocado, pelo aumento da produção agrícola. Isso culminou, no surgimento das cidades como, Uruk atraía as massas para lá.

O grão reclamará o celeiro; o celeiro exigirá uma muralha para proteger e um exército para defender a muralha, um escriba para contar os sacos de trigo, fixar os impostos e escrever a história (GOURHAN, 1987, p 146).

\subsection{SURGIMENTO E A IMPORTÂNCIA DAS GRAMÍNEAS}

De acordo com os paleontólogos, as gramíneas surgiram no registro fóssil por volta de 25 milhões de anos, no final do Período Oligoceno para o Mioceno.

The wet and dry seasons of the Miocene climate ensured that large areas of the planet became covered in vast grasslands. It is not easy for animals to digest grass, so herbivores had to evolve new types of teeth and digestive system to take advantage of its abundance[6] (HAINES; CHAMBERS, 2005, p 149).

Seu aparecimento levou a extinção de grandes predadores de emboscadas (como o Entelodont), que não corriam em longas distâncias para alcançar suas presas, logo foram afetados. Com a diminuição de florestas temperadas e a propagação dessas plantas originaram-se savanas e campos abertos, em boa parte da Eurásia. Aos poucos, o Entelodont se tornou extinto, devido à competição com o cão-urso mais veloz e adaptado a longas corridas para perseguir suas presas (HAINES, 2001).

RC: 86090

Disponível em: https://www.nucleodoconhecimento.com.br/historia/caso-do-dinosauroid 
Enquanto isso, essa planta, que evoluiu na Ásia espalhou-se pelo resto do mundo provocando o aparecimento de novos herbívoros que se alimentavam delas.

They also had to be able to travel great distance to find fresh areas of grass and escape predators on the open plains. So, by the midMiocene, fast moving grazing mammals had evolved on all the temperate continents[7] (HAINES, 2001, p. 121).

Sem dúvida, com o surgimento das gramíneas levou ao aparecimento de novos predadores (felinos, canídeos, hienas e outros) e também, surgiram novas presas (bovinos, equinos, caprinos, suínos e outros). Quando os humanos começaram a domesticar as plantas e logo precisavam domesticar determinados animais (para ajudar na produção agrícola: bovinos e equinos). A combinação destas duas domesticações provocou o aparecimento de uma sociedade mais complexa e tudo isso somado, nos levou a: medicina, astronomia, matemática, história, filosofia e ciências.

\subsection{INTELIGÊNCIA E CRIATIVIDADE OBSERVADA NO MUNDO ANIMAL}

Nossa espécie surgiu entre: 300 a 200 mil anos permanecendo, por muito tempo: caçadores e coletores[8]. A agricultura de larga escala de tubérculos e gramíneas surgiu muito recentemente, por volta de 10 mil anos, no Crescente Fértil. Mesmo que hipoteticamente, os Saurornithoides que viessem evoluir para o Dinosauroid, esse "camaradinha" para sobreviver necessitava de ter uma inteligência similar ao dos humanos. Entender o mundo sem sua volta (posição das estrelas, ler pegadas de animais de casco, entender a época certa para pescar peixes e mexilhões e saber se comunicar uns com os outros usando linguagem articulada com sintaxe). Nenhum animal na natureza tem tantas habilidades iguais a nossa linhagem.

Porém, existem animais como: os corvos, os polvos, os chimpanzés e os elefantes que demonstram ter certas, habilidades, como: sentimentos (amor, luto, cooperação, carinho e outros), inteligência (de curto e longo prazo), comunicação e criação de

RC: 86090

Disponível em: https://www.nucleodoconhecimento.com.br/historia/caso-do-dinosauroid 
ferramentas para buscar alimentos. Tudo isso já foi registrados em vídeo e publicados em artigos e simpósios[9].

No caso dos Saurornithoides que é um dinossauro bípede e inteligente teria de mudar sua bipedia, para uma postura mais ereta, similar ao gênero: Homo. A nossa bipedia teria um plano vertical (devido nosso centro de gravidade), que é diferente da bipedia desse dinossauro que tem um plano horizontal, similar uma galinha. Concluindo, para o Dinosauroid viesse a emergir, deveria ter um ancestral, que pelo menos tivesse uma locomoção quadrúpede palmígrada (sugestão atestada, por alguns estudiosos, sobre qual seria a origem dos hominínios da linhagem humana).

FIGURA 2.1 - A figura abaixo mostra o centro de gravidade do ser humano e da galinha. O plano de locomoção humano é vertical (ereto), enquanto a galinha é horizontal.
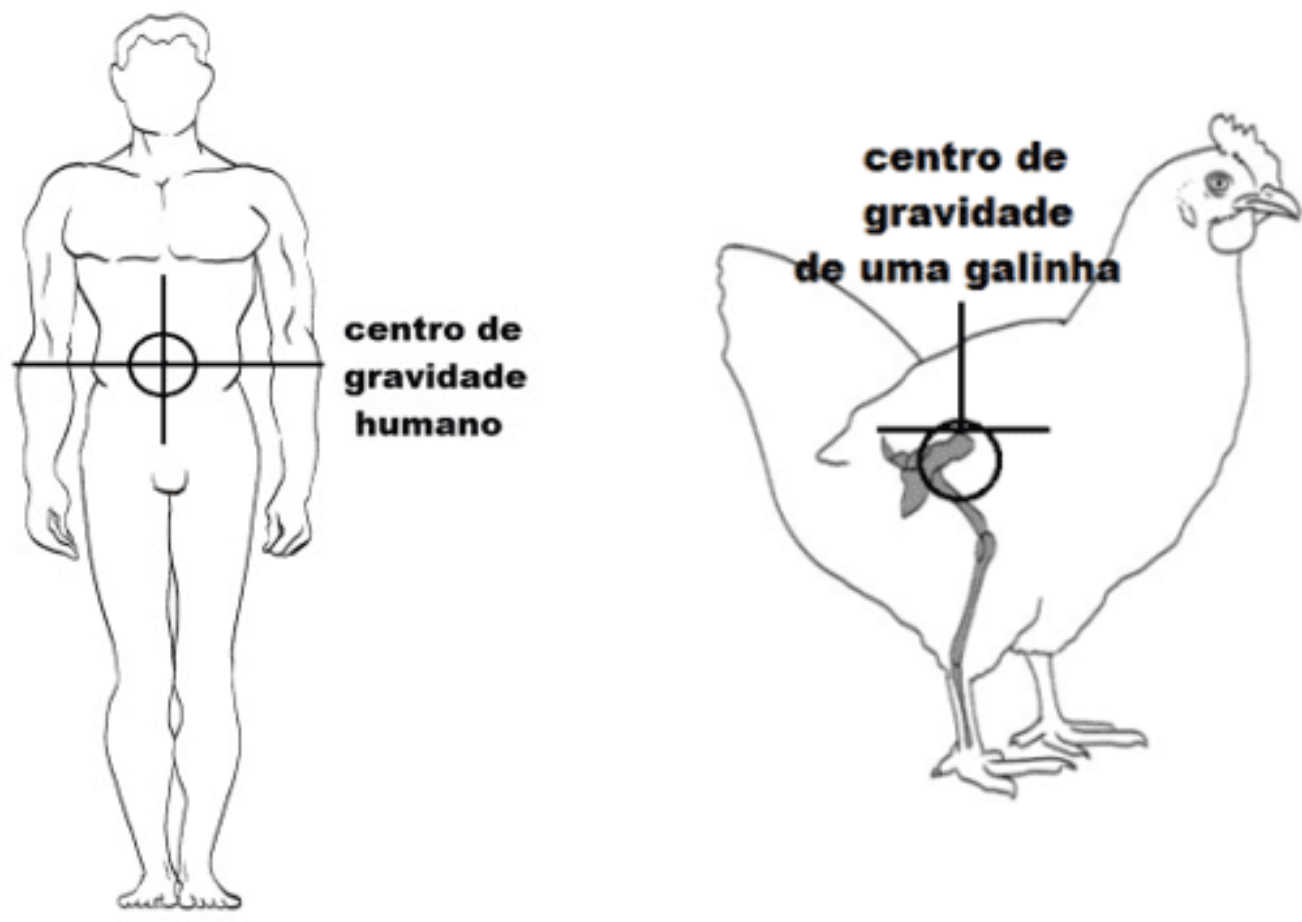

Ilustração de Felipe Lima Simões.

RC: 86090

Disponível em: https://www.nucleodoconhecimento.com.br/historia/caso-do-dinosauroid 


\subsection{O DINOSSAUROID}

Figura 2.2 - O dinossauroid completamente com uma locomoção humana no plano vertical (ereto) de acordo com Dr. Dalle Russell e Séguin (1982).

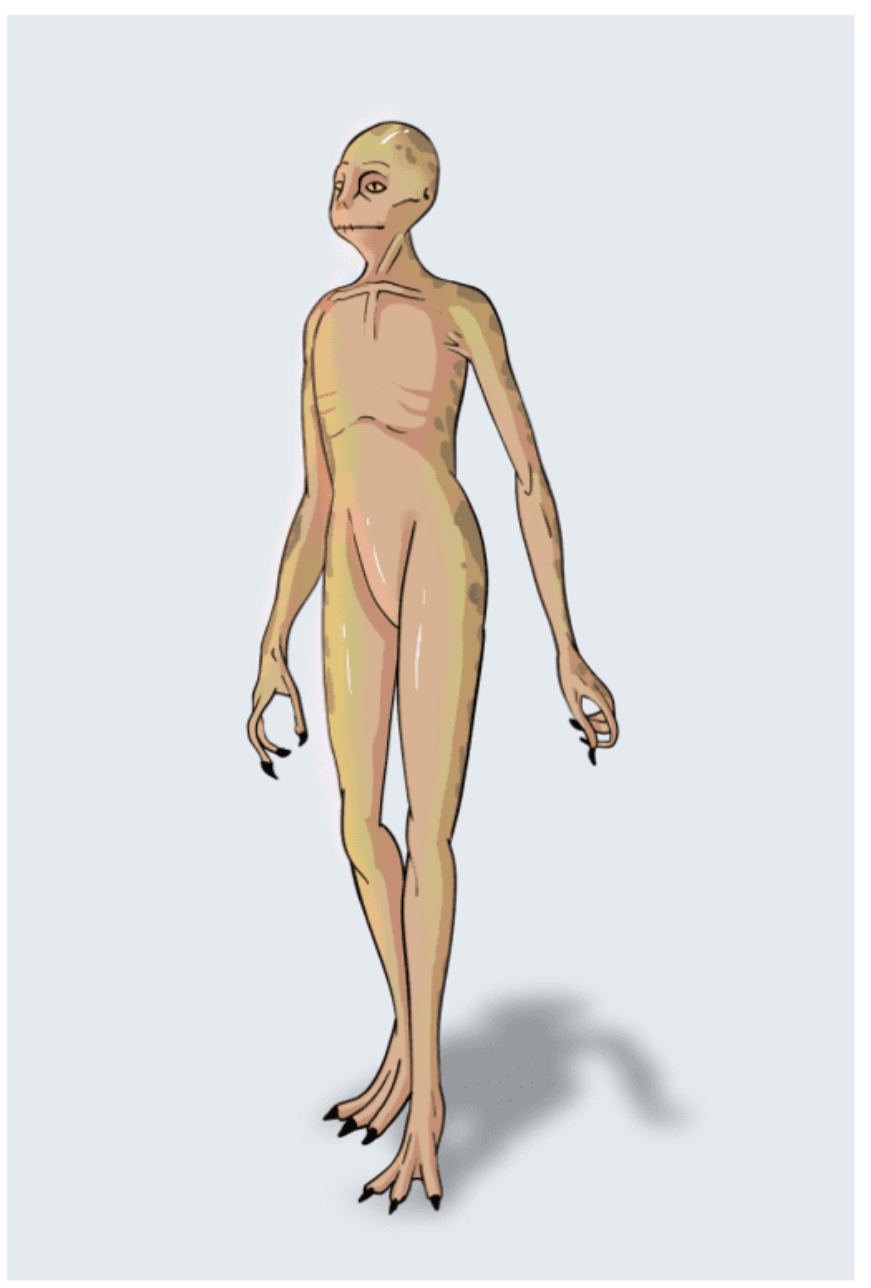

Ilustração de Danilo Barros.

Em 1982, o paleontólogo canadense, Dr. Dale A. Russell da Universidade Estadual da Carolina do Norte e o taxidermista Ron Séguin, escreveram um artigo para a revista: Syllogeus do Museu Nacional de Ciências Naturais do Canadá, indo muito mais além, que Carl Sagan havia começado. Eles propuseram um experimento mental que até hoje gera polêmica no meio científico. Mas, ao mesmo tempo, é muito divertido e educativo, longe de ser chato ou embaraçoso.

RC: 86090

Disponível em: https://www.nucleodoconhecimento.com.br/historia/caso-do-dinosauroid 
Só para esclarecer um experimento mental é um exercício que envolve: muita argumentação, lógica e imaginação para solucionar problemas hipotéticos. Há, como exemplos: o Gato de Schrödinger na Física e a Caverna de Platão, na Filosofia. Quando Dr. Russell e Séguin (1982) propuseram que os Troodontidae em condições corretas poderiam dar origem ao Dinosauroid que seria uma criatura com locomoção ereta produzindo ferramentas líticas graças ao seu cérebro grande (assemelhando-se com as sociedades tribais africanas, como: Khoisan).

This general shape was retained as the endocranial volume was increased to $1,100 \mathrm{ml}$ to equal that of the skull of a small human female skeleton in the collections of the Paleobiology Division[10]. (RUSSELL; SÉGUIN, 1982, p 22).

Russell e Séguin sugeriram inicialmente, que Stenonychosaurus inequalis que atualmente, é a espécie do Troodon[11] seria o dinossauro que daria origem ao Dinossauroid. O Troodon viveu no Cretáceo Superior, onde hoje em dia são os Estados Unidos, Canadá e Alasca (Hemisfério Norte), são onívoros (HOLTZ et al, 1998), e é primo dos Saurornithoides (espécie sugerida por Carl Sagan). Os dois pertencem à mesma família dos Troodontidæ. Por que o Dr. Russell e Dr. Séguin escolheram os Troodontidæ para dar origem ao Dinossauroid? Por acaso, não havia outros dinossauros, como Velociraptor da Mongólia[12]? Os Velociraptores viveram por um breve período de tempo, entre: 75-71 milhões de anos, enquanto, os Troodontidæ, viveram entre: 75-65 milhões de anos. Um tempo maior para dar estabilidade morfológica à espécie. Outro fator interessante seria a relação entre o tamanho do corpo e o cérebro. Nos Troodontidæ isso é muito mais acentuada, do que os demais dinossauros (RUSSELL; SÉGUIN, 1982).

\section{COMO OS HOMINÍNIOS TIVERAM UM CÉREBRO GRANDE?}

Na época em que Dr. Russell e Séguin propuseram o Dinosauroid, ainda não existia estudos para explicar o que teria provocado o aumento da capacidade cerebral no gênero: Homo. Atualmente, sabemos que para ter um cérebro grande não significa ser mais inteligente do reino animal. Como já foi dito: os mamíferos (elefantes,

RC: 86090

Disponível em: https://www.nucleodoconhecimento.com.br/historia/caso-do-dinosauroid 
macacos e canídeos), as aves e os polvos além de serem inteligentes, também criam linha de ação de curto e longo prazo; tem memória de curta e longa duração, além de criarem diversas ferramentas para obter comida e construir abrigos. Muita gente pensa cérebro grande significa mais inteligência. Na biologia não é bem assim.

Para que o Dinossauroid tivesse de fato um cérebro com as cognições humanas, então, temos de entender o que provocou o desenvolvimento cerebral. Ora... O Dr. Russell ao publicar seu trabalho, não conseguiu explicar como isso aconteceu. Entre: 7,0 milhões de anos até 2,0 milhões de anos, os nossos ancestrais mais primitivos deste período de tempo tinham aproximadamente a mesma média, de volume cerebral: 350-450cc (NEVES et al, 2015). Então a partir de 2,0 milhão de anos, a capacidade cerebral dobrou de tamanho indo para 900cc. Foi um aumento muito abrupto, em tão pouco tempo. Qual seria a explicação disso? Só recentemente podemos responder graças às pesquisas da Dra. Suzana Herculano-Houzel da UFRJ e do Dr. Richard Wrangham.

Se formos analisar friamente, a nossa evolução e a dos Troodontidæ, vamos perceber que ambas tiveram características e ancestrais diferentes. Não dá para falar de aumento da capacidade cerebral, sem aportar o dedo, naquele agente causador: o cozimento ou o uso fogo controlado (fogueira) para assar a carne e outras comidas.

O "Menino de Turkana" de 1,6 milhões de anos tinha um volume cerebral de $900 \mathrm{cc}$ e provavelmente, sua espécie conseguiu obter o controle do fogo (fogueiras controladas). Em por volta de 1,0 milhão de anos, o volume craniano dessa espécie aumentou para: 1000 e 1100cc (Homo erectus da China).

Dr. Richard Wrangham em seu livro: "Pegando Fogo" (2010) sugere que a digestão é muito mais rápida nos alimentos tratados pelo calor do fogo, o que permitia uma economia de tempo e mais energia ao corpo, assim os primeiros cozinheiros poupava energia para as funções cerebrais. Com esse aporte extra de energia, com o tempo, levou, ao crescimento do cérebro, redução da face prognata e o desenvolvimento da proto-linguagem e posteriormente, a cognição. Com a dieta baseada em cozimento RC: 86090

Disponível em: https://www.nucleodoconhecimento.com.br/historia/caso-do-dinosauroid 
provocou a diminuição dos intestinos do Homo erectus clássico, em relação a outros primatas (o apêndice humano atrofiou tornando-se um órgão inútil). No que diz respeito à economia de tempo - passamos menos tempo comendo e mais horas realizando outras atividades, como: caminhar, pescar e caçar. Gastamos energia para pintar cavernas ou fazer pingentes. Para efeito de comparação, os chimpanzés e gorilas, passam cerca de seis (6) horas por dia se alimentando (WRANGHAM, 2009, p 110).

\footnotetext{
Uma pessoa inativa, cada quinta refeição é ingerida unicamente para prover o cérebro de energia. Literalmente, nossos cérebros usam cerca de $20 \%$ de nossa taxa metabólica basal nosso orçamento energético quando estamos em repouso -, embora constituam apenas $2,5 \%$ de nosso peso corporal. Sendo os cérebros humanos tão grandes, essa proporção de gasto energético é a mais alta que em outros animais (WRANGHAM, 2010, p 88).
}

0 " $x$ " da questão é que quando passamos a usar o cozimento, o cérebro aumentou de tamanho. Exemplificaremos. Os Neandertais clássicos, como de: La Chapelle tinha por volta de 1500-1700cc de volume cerebral. Existem provas arqueológicas de que eles usavam fogueira controlada para cozinhar alimentos (STRINGER, 2012, p 114145). $85 \%$ de sua dieta era a base de carne (Discovery Channel: The Last Neandertal? 1996). Isso demonstra que a Dra. Suzana Herculano-Houzel e o Dr. Wrangham estariam corretos em sugerir que o cozimento libera mais proteínas. A carne tratada no calor do fogo mata bactérias e parasitas na gordura animal ficando livre para o seu consumo (STRINGER, 2012). Isso explica, porque Neandertal tinha um cérebro maior, em relação a nossa espécie: o Homo sapiens.

\subsection{ESTABILIDADE MORFOLÓGICA}

Voltando para o Troodontidæ sabemos que ele viveu no Hemisfério Norte por 10 milhões de anos, sem alterações em sua anatomia. Para Gould isso é uma prova de estabilidade morfológica, proposta pela "Hipótese do Equilíbrio Pontuado" (CARVALHO, 2000). Mas no tocante a sua capacidade cerebral ao comparado com cérebros de outras espécies ou até das aves, notou-se que seu volume cerebral era

RC: 86090

Disponível em: https://www.nucleodoconhecimento.com.br/historia/caso-do-dinosauroid 
maior (JERISON, 1973). Sua bipedia não sofreu alterações morfológicas profundas, o mesmo pode ser dito de sua capacidade cerebral ficando inalterado longo de milhares de anos. Ora... Não tem como o Troodontidæ evoluir para um ser semelhante ao um humanoide, pois não houve o desenvolvimento do andar ereto e nem do cozimento. Os processos evolutivos desses dinossauros e do aparecimento do gênero: Homo foram diferentes, pois suas estratégias, comportamento e habilidades eram diferentes.

\subsection{A REAÇÃO DA COMUNIDADE CIENTÍFICA}

Num blog publicado em 2006, por Naish[13] considerou que Russell e Séguin teriam percebido que os dinossauros da família dos Troodons a qual o Saurornithoides faz parte, tinham dentes pequenos. Menores do que os demais dinossauros da época (essa redução dentária nada tem a ver com a dentição de $A r d l)$. Esta evidência fez com que Dr. Russell sugerisse que os Troodontidæ com o passar do tempo daria origem ao Dinossauroid, pois não teriam dentes similar as aves modernas.

Based on the idea that troodontids had a reduced dentition compared to other theropods, and on the notion that big-brained primates have a reduced dentition compared to smaller-brained forms, they made the dinosauroid toothless[14] (Dinosauroids revisited, 2006).

Those large, staring eyes of an intelligent gecko, the wide turtle mouth, the scaly-skinned humanoid from, three long, flexible fingers ending in formidable claws... the viewer experiences a disorienting jolt of déjà and jamais vu, as belief vies with incredulity[15] (MAYERS, 2000, p 249).

Com a dentição reduzida, Russell e Séguin propuseram que o Dinossauroid teria um crânio similar de um embrião de galinha, com olhos e boca grande (RUSSELL; SÉGUIN, 1982). Lovejoy explica o que levou a bipedia e os caninos reduzidos foi à interação entre os machos e fêmeas, que tinham como preferência o transporte de mais alimentos (LOVEJOY, 2009). Porém, não conseguimos ver essas características e suas estratégias, no extinto ancestral do Dinossauroid - os Troodontidæ.

Observando o comportamento das aves percebemos que elas utilizam muito a boca e os pés para buscar o seu alimento (NAISH, 2006). Os membros superiores (as RC: 86090

Disponível em: https://www.nucleodoconhecimento.com.br/historia/caso-do-dinosauroid 
assas) dos galináceos só usados na época de acasalamento e intimidação de predadores. Isso sugere e reafirma que as estratégias de sobrevivência, entre: o Troodon aviário e de Ardi são completamente incomparáveis. Não sendo possível haver uma evolução de um dinossauro para um humanoide como o Dinossauroid.

Apesar do paleoclima do Cretáceo Superior sendo quente e úmido com uma vegetação que lembra florestas e bosques temperados (naquela época, não havia gelo nos polos), mesmo nessas condições seria muito improvável tal evolução acontecer. Não vemos a utilidade dos membros superiores dos Troodontidæ usados com a finalidade de buscar alimentos usando as mãos, para dividir o alimento numa Home Base no intuito de buscar uma parceira e se reproduzir.

Caso não houvesse a extinção dos dinossauros a 65 milhões de anos podemos afirmar com segurança, que haveria mais criaturas semelhantes às aves habitando o globo, do que espécies de um mamífero de andar ereto e cultura humanoide. O motivo de pensar assim é de acordo com as evidências de campo, proposta pelo paleontólogo, Dr. David Varricchio, que nos anos 90, escavou junto com Dr. "Jack" Horner (1997) descobrindo dezenas de ninhos de Troodontidæ próximos aos ninhos de Maiasaurus (dinossauro herbívoro). Os filhotes desses dinossauros ao nascer já tinham dentes para se alimentar de carne.

Foram encontrados ninhos fossilizados de Troodon em Montana, no sítio de fósseis: Montanha de Ovos. Alguns ninhos contêm ovos completos, e poucos ovos têm esqueletos de filhotes de Troodon. Às vezes são achados ossos de um Troodon adulto junto aos ninhos, fazendo supor que ele se sentasse sobre os ovos para mantê-los aquecidos (BARRETT, 2002, p 170).

Isso demonstra que há muitas semelhanças entre as aves e os Troodontidæ. A disposição dos ovos nos ninhos, a anatomia e biologia e o possível comportamento que esses dinossauros tinham que podem ser similar ao das aves.

RC: 86090

Disponível em: https://www.nucleodoconhecimento.com.br/historia/caso-do-dinosauroid 


\section{CONCLUSÃO}

Vimos que ao longo do texto, que o comportamento e as estratégias de sobrevivência dos Troodontidæ seriam mais próximos ao das aves, mesmo num paleoambiente semelhante ao dos primeiros hominínios. Isso porque, seguimos por um caminho evolutivo diferente desse dinossauro. Somos incrédulos em pensar que alguma coisa parecida com um humanoide viesse a surgir no processo evolutivo de um ancestral aviário sugerido, por Russell e Séguin, mas seu experimento mental foi muito interessante e divertido.

No que diz respeito à evolução na nossa linhagem, Lovejoy (2009) considera que havia uma relação entre: transporte de alimentos, escolha de uma parceira, ajudou na redução de caninos e de algum modo floresceu a origem do bipedalismo. Também foi notado que houve a redução dentária entre os Troodontidæ, mas ao que parece seu comportamento, anatomia e estratégias não teria sido alterado ficando estável, por mais de 10 milhões de anos sugerindo a estase, proposta pelo Equilíbrio Pontuado.

No caso dos humanos, o crescimento encefálico iniciado com os primeiros humanos, segundo a Dra. Suzana Herculano-Houzel da UFRJ e o Dr. Richard Wrangham consideraram que o cozimento foi um gatilho para isso, que nos levou a cognição.

O que explica a estabilidade morfológica dos Troodontidæ seria que: $1^{\circ}$ não era bípede ereto e nem utilizava do cozimento, como estratégia de sobrevivência. Muito provavelmente, seus membros superiores (braços e mãos) não eram como dos humanos (não possuíam dedos prênseis, como Ardi). Por outro lado, a falta do cozimento, no início da evolução humana, também explica a estabilidade morfológica cerebral tendo em média: 350-450cc, entre os primeiros hominínios (préaustralopitecíneos e os australopitecíneos), durante um intervalo de tempo de 7,0 a 3,0 milhões de anos.

Mesmo que a locomoção ereta seja mais ou menos semelhante, esteja presente em apenas uma única espécie de ave, o pinguim e mesmo assim, essa ave é marinha.

RC: 86090

Disponível em: https://www.nucleodoconhecimento.com.br/historia/caso-do-dinosauroid 
Mas voltando ao tema. Quando os primeiros humanos modificaram a relação comportamental, de habitat, sexual e a estratégia de sobrevivência, provocou um salto na evolução humana, que talvez tivesse como causa disso: o cozimento.

No que tange aos Troodontidæ podemos afirmar que eles ficaram por muito tempo em estabilidade biológica, por que mantiveram a mesma estratégia de sobrevivência e as mesmas características comportamentais. Com isso podemos afirmar que é improvável, esse dinossauro evoluir para algo humanoide similar ao Dinosauroid.

\section{REFERÊNCIAS}

ALVAREZ, L. W. et al. Extraterrestrial cause for the Cretaceous-Tertiary extinction. Science 208, 1980. P 1095-1108.

ARGUE, D. Did LB1 (Homo floresiensis) have Down Syndrome? Australia, Australian Archaeological Association Annual conference, 2014.

ARGUE, D. et al. Homo floresiensis: a Cladistics Analysis. Journal of Human Evolution 57, 2009, p 623-639.

AIELLO, Leslie. C. Five years of Homo floresiensis. American Journal of Physical anthropology V. 142, 2010, P 167-179.

BARRETT, Paul. Dinossauros. In: Troodon. São Paulo: Martins Fontes, 2002. P 170171.

BROWN, P; MORWOOD, M; SUTIKNA, T. A new small-bodeied hominid from the late Pleitocene of Flores, Indonesia. Nature. Vol 431: 2004. P 1055-1061.

CARVALHO, I.S (org). Paleontologia. In: IANNUZZI, R \& SOARES, Marina: Teorias evolutivas. Rio de Janeiro: Interciencia, 2000. P 61-81.

RC: 86090

Disponível em: https://www.nucleodoconhecimento.com.br/historia/caso-do-dinosauroid 
DISCOVERING ARDI (Descobrindo Ardi PT-BR). Diretor: Rod Paul. Produtores: David Paul e Paul Gasek. Escritores: Jonathan Wickham e Steve Eder. Discovery Channel. Formato: AC-3, Colorido, Dolby, DVD, Widescreen, NTSC. Linguagem: inglês. Legenda: Português. Região: 4 (América Latina). 88 minutos. Março de 2010.

HEINES, Tim e CHAMBERS, Paul. The Complete Guide to Prehistoric Life. In: Part Three The Age of Beasts. Buffalo, Firefly Books, 2005. P 144-149.

HEINES, Tim. Walking with Beasts: A Prehistoric Safari. In: Land of the Giants. New York, DK, 2001. P 100-121.

JERISON, HARRY J. Dinosaur Brains. The American Naturalist. Volume: 103, № 934, Novembro e Dezembro de 1969, p. 575-588.

JUNGERS, W. L. et al. The foot of Homo floresiensis. Nature, V 459, 2009, P 81 84.

HOLTZ Jr, Thomas R et al. Denticle Morphometrics and a Possibly Omnivorous Feeding Habit for the Theropod Dinosaur Troodon. Gaia no 15, Lisbon, dezembro 1998, p. 159-166.

KENSKI, Rafael. O pio do Dinossauro. Superinteressante. São Paulo: Abril. Ano 14. No 7. Julho de 2000. P 30-36.

KRIWACZEK, Paul. Mesopotâmia: A Mesopotâmia e o Nascimento da Civilização. Rio de Janeiro: Zahar, 2018.

LEAKEY, Richard e LEWIN, Richard. O Povo do Lago. $2^{\underline{a}}$ ed. Brasília: UnB, 1996.

LEONARD, William R e ROBERTSON, Marcia L. Locomotor Economy and the Origin of Bipedality: Reply to Steudel-Numbers. American Journal Of Physical Anthropology. Volume: 116. 2001, p 174-176.

LEROI-GOURHAN, André. Os caçadores Pré-históricos. Lisboa: Edições 70, 1987. RC: 86090 
LOVEJOY, Owen C. The Origin of Man. Science. Vol 211. №4480, 1981. P 341-350.

LOVEJOY, Owen C. Reexamining Human Origins in Light of Ardipithecus ramidus. Science, Vol 326. 2010. P 74-74e8.

LOVEJOY, C. Owen. Evolution Human Walking. Scientific American. November 1988. p 118-125.

LEONARD, William R e ROBERTSON, Marcia L. Locomotor Economy and the Origin of Bipedality: Reply to Steudel-Numbers. American Journal of Physical Anthropology. Volume: 116. 2001, p 174-176.

MAYERS, Adrienne. The First Fossil Hunters. In: The Human-Dinosaur, Princenton, 2000. P 248-253.

NAISH, Darren. Dinosauroids revisited. Darren Naish: Tetrapod Zoology, 2007. Disponél em: <http://darrennaish.blogspot.com.br/2006/11/dinosauroidsrevisited.html> Acesso em: 12/03/2018.

NEVES, Walter, RANGEL JUNIOR, Miguel e MURRIETA, Rui Sérgio S (org.). Assim Caminhou a Humanidade. In Capítulo IV. NETO, Clóvis Monteiro, GLÓRIA, Pedro e NEVES, Walter Alves. Origem e Dispersão do Gênero Homo. São Paulo: Palas Athena, 2015. P 146-188.

NEVES, Walter Alves e PILÓ, Luis B. O Povo de Luzia. Rio de Janeiro: Globo, 2008.

OS 10 ANIMAIS MAIS INTELIGENTES. Youtube, [S. I.: s. n.] 1 vídeo (10min). Publicado pelo Canal: Refúgio Metal. Disponível em: $<$ www.youtube.com/watch?v=I3nVa-VC_Z8> Acessado em: 11 de setembro de 2019.

PALEOWORLD: TROODON: DINOSAUR GENIUS (Paleomundo: Troodon, o Dinossauro Gênio - PT-BR) Diretor: Brendan Hughes. Produtor da série: Joanne Reay. Produção da: Discovery Channel e Wall to Wall Television for The Learning Channel.

RC: 86090

Disponível em: https://www.nucleodoconhecimento.com.br/historia/caso-do-dinosauroid 
Episódio 13 da $2^{\mathrm{a}}$ temporada. Colorido, VHS, NTSC. Linguagem: Inglês. 22 minutos. 1995.

PALEOWORLD: BABY MONSTERS (Paleomundo: Bêbes Monstros - PT-BR) Diretor: Brendan Hughes. Series Producer: Alex West. Produção de: Discovery Channel e Wall to Wall Television for The Learning Channel. Episódio 04 da 04a temporada. Color. VHS, NTSC. Linguagem: Português. 23 minutos. 1997.

PREHISTORIC PREDATORS: KILLER PIG (Predadores Pré-históricos: Porco Assassino - PT-BR) Editor: Julio Moline. National Geographic Channel. Colorido. NTSC. Linguagem: Português. 46 minutos. 2009.

RUSSELL, D. A.; SÉGUIN, R. Reconstruction of the small Cretaceous theropod Stenonychosaurus inequalis and a hypothetical dinosauroid. Syllogeus 37: 1982, p 1 43.

SAGAN, Carl. Os Dragões do Éden. In: Os Contos do Éden Sombrio. Lisboa: Gravida, 1985. P 53-65.

SOBOUL, Albert. A Revolução Francesa. In: Introdução: Flutuações Econômicas e Demográficas. Rio de Janeiro: Difel, 1976, p 07-40.

STRIGER, C. Lone Suvivor. New York: Henry Holt, 2012.

THE LAST NEANDERTHAL? (O Homem de Neandertal: Origem e Extinção - PT-BR) Diretor: Lwarence Simanowitz. Produtor: Willian Woodllard. Editor: Sabrina Burnard. Discovery Channel e An Inca Production for Channel Four in Association with Discovery communications Inc. NTSC. Linguagem: Dublado, cor, 45min, VHS. 1996. WARD, Peter. O Fim da Evolução. Rio de Janeiro: Campus, 1997. 
VANNUCCI, Robert C. BARRON, Todd F. e HOLLOWAY, Ralph L. Craniometric ratios of microcephaly and LB1, Homo floresiensis, using MRI and endocasts. PNAS, vol. 108 no. 34. August 23, 2011. P 14043-14048.

VARRICCHIO, David J et al. Nest and egg clutches of the dinosaur Troodon formosus and the evolution of avian reproductive traits. Nature. Vol. 385. 1997. P 247-250.

VARRICCHIO, David $J$ et al. Embryos and eggs for the Cretaceous theropod dinosaur Troodon formosus. Journal of Vertebrate Paleontology 22 (3): 2002. P 564-576.

WONG, Kate. Encontro de uma nova espécie. Scientific American Brasil. Edição Especial. In. Ardi tinha características humanas? Rio de Janeiro: Duetto. № 37. 2010. P 18-19.

WRANGHAM, Richard. Pegando Fogo: Por que Cozinhar nos Tornou Humanos. Rio de Janeiro, Zahar, 2010.

\section{APÊNDICE - REFERÊNCIA DE NOTA DE RODAPÉ}

2. Tradução: Essa mudança provavelmente de conflito reduzido entre os machos e combinada com três inéditos comportamentos associados à sua capacidade de explorar tanto as árvores e como na superfície da terra: (1) transporte regular de alimentos, (2) ligação de parceiros, e (3) reprodução (em que as fêmeas não anunciam a ovulação, ao contrário do caso dos chimpanzés).

3. Tradução: Finalmente, o contexto ambiental do Ardipithecus sugere que seu habitat primário, não era uma savana ou pastagens, mas eram as florestas.

4. Tradução: Ar. ramidus era plenamente capaz de bipedalismo e tinha evoluído substancialmente a pélvis modificando com pé a qual andava ereto. Ao mesmo tempo, preservada a capacidade de manobrar em árvores, pois manteve agarrando o dedão

RC: 86090

Disponível em: https://www.nucleodoconhecimento.com.br/historia/caso-do-dinosauroid 
do pé e um poderoso quadril e musculatura da coxa. Porque o andar vertical não fornecia nenhuma vantagem energética para Ar. ramidus (faltou muita das adaptações evoluírem nos hominídeos posteriores, tais como Australopithecus), o sucesso reprodutivo deve ter sido fundamental para sua evolução dos primeiros hominídeos.

5. Carnívoro de 3 metros de comprimento, 1 metro de altura e pesando $45 \mathrm{~kg}$, descoberto na Mongólia datado entre: 75-65 milhões de anos.

6. Tradução: As estações secas e úmidas do clima Mioceno garantiu que grandes áreas do planeta tornaram-se coberto de vastas pradarias. Não é fácil para os animais de digerir grama, assim herbívoros tinham que evoluir novos tipos de dentes e o sistema digestivo para tirar proveito de sua abundância.

7. Tradução: Eles também tiveram que ser capaz de viajar grandes distâncias para encontrar áreas novas de grama e escapar de predadores nas planícies abertas. Assim, até meados do Mioceno, em movimento rápido mamíferos de pastagem tinha evoluído em todos os continentes temperados.

8. Atualmente, existem populações humanas com cultura caçador-coletora - serão citadas as mais conhecidas, como: Khoisan e !Kung, na África. Na Ásia, os Papuas e na América: Xingu e lanomânis.

9. Youtube: Refúgio Metal: Os 10 Animais Mais Inteligentes: www.youtube.com/watch?v=|3nVa-VC_Z8

10. Tradução: Esta forma geral foi mantida como o volume endocranial foi aumentado para $1.100 \mathrm{~cm}^{3}$ para igualar a do crânio de um pequeno esqueleto humano feminino nas coleções da Divisão Paleobiologia.

11. Possuí 1 metro de altura por 2,4 metros de comprimento, pesando cerca de: 45 $50 \mathrm{~kg}$.

12. "Lagartos Corredores" que caçavam em bando como os lobos fazem.

RC: 86090

Disponível em: https://www.nucleodoconhecimento.com.br/historia/caso-do-dinosauroid 
13. http://darrennaish.blogspot.com.br/2006/11/dinosauroids-revisited.html

14. Tradução: Com base na ideia de que troodontídeos tinha uma dentição reduzida em comparação com outros terópodes, e na noção de que os primatas grandes cérebros têm uma dentição reduzida em comparação com as formas menores cérebros, eles fizeram o desdentado Dinossauroid.

15. Tradução: Aqueles grandes olhos, olhando de um Gekco inteligente, a boca tartaruga larga, o humanoide de pele escamosa de três, dedos longos flexíveis que terminam em garras formidáveis... O espectador experimenta um choque desorientador de déjà vu, como a crença concorre com incredulidade.

Enviado: Setembro, 2020.

Aprovado: Maio, 2021.

RC: 86090 